\title{
THE ANALYSIS OF THE INFLUENCE OF RIVETING PARAMETERS SPECIFIED IN SELECTED RIVETING INSTRUCTIONS ON RESIDUAL STRESSES
}

\author{
Wojciech Wronicz \\ Jerzy Kaniowski \\ Institute of Aviation, Al. Krakowska 110/114, 02-25 Warsaw, Poland \\ wojciech.wronicz@ilot.edu.pl, jerzy.kaniowski@ilot.edu.pl
}

\begin{abstract}
The riveting parameters strongly affect residual stresses induced during riveting, which in turn have an impact on the fatigue life of riveted joints. Since rivets are established as critical from the fatigue point of view, the fatigue life of riveted joints often determines the life of the whole structure.

The authors were able to become acquainted with three riveting instructions (process specifications) used by the aerospace companies from western Europe. This work presents the analysis of the riveting parameters' influence on residual stresses around the rivets. The impact of the clearance between a rivet shank and a hole as well as driven head dimensions and a rivet length were investigated based on the numerical simulations. The aim of the analysis was to determine the range of stresses variation when the requirements of the riveting instructions are fulfilled. For the purposes of comparison, the calculations were performed also with the parameters as specified in the Polish industry standards. For all calculations, the geometry of the universal rivet MS20470 was used.

The results show that residual stresses can vary strongly depending on the parameters in the instructions and standard requirements.
\end{abstract}

Keywords: Riveting, residual stress, FEA, simulation

\section{INTRODUCTION}

Riveting joints represent a critical area of a structure in respect of fatigue crack nucleation. The fatigue life of riveted joints often determines the fatigue life of a whole structure. This is the reason that rivet installation requires special care and is performed by qualified technicians according to internal instructions (process specifications).

The fatigue life of riveted joints depends on the joint geometry, including the rivet shape $[1,2]$, and a range of technological factors, of which the squeezing force is particularly important. The clearance between the rivet shank and the hole is also considered an important factor [5]. This is connected with residual stresses induced during riveting around the rivet hole. Radial stresses are always compressive. The sign of the tangential stresses depends on squeezing force, rivet type, clearance and distance from the rivet. Compressive stresses are beneficial because they restrict fatigue crack nucleation and growth, which consequently increases the fatigue life of a joint. 


\section{THE AIM AND SCOPE OF THIS WORK}

The authors were able to become acquainted with three riveting instructions used by the aerospace companies from western Europe, referred to in this paper, due to the requirements of confidentiality, as West1 (W1), West2 (W2) and West3 (W3). The paper [6] contains the analysis of requirements in these instructions.

The influence of the riveting technological parameters was investigated by a number of researchers $[3,4,5,7,8]$. In this paper, the authors analysed a range of a stress variation when the requirements of the instructions are fulfilled for a selected rivet type, diameter and sheet thickness. The analysis concerned a hole diameter, rivet length, driven head diameter and height specified in the instructions as well as the rivet shank diameter specified in the rivet standard. The analysis was performed with FE calculations.

Selected for the investigation was the universal MS20470 rivet with the $3.2 \mathrm{~mm}$ diameter made of 2117 aluminium alloy which joints two sheets made of 2024 T3 aluminium alloy with a nominal thickness of $1.27 \mathrm{~mm}$. For the purposes of comparison, additional calculations were made with the parameters according to the Polish industry standard BN-70/1120-03 defining the rivet length, driven head diameter and height as well as the hole diameter. According to this standard, the tolerance of a hole diameter is equal to $+0.1 \mathrm{~mm}$ for a rivet diameter of $3.0 \mathrm{~mm}$ and +0.15 for a rivet diameter of $3.5 \mathrm{~mm}$. The authors decided to use a clearance of $0.12 \mathrm{~mm}$ for the analysed rivet with a diameter of $3.2 \mathrm{~mm}$. Moreover, the geometry of the universal rivet MS20470 was used, but a shank diameter tolerance defined by the Polish industry standard for the aerospace brazier head rivets BN-70/1121-06 was adopted. The MS20470 standards require a chamfer or a radius at the shank edge when according to the Polish BN-70/1121-06 standard, the shank is cut perpendicular to its axis. In view of this fact, the calculations with the parameters according to the Polish standards were performed on the model without a radius on the shank end. These calculations, marked as 'BN' were performed only for the case of the minimal clearance between the rivet and the hole (maximum rivet diameter and minimum hole diameter).

\section{FE MODEL}

The FE model of the riveted joint was prepared with the use of four-node axisymmetric elements (Fig. 1). It contained the rivet and the surrounding area within a radius of $50 \mathrm{~mm}$. The model consisted of about 6, 500 elements and 7, 000 nodes.

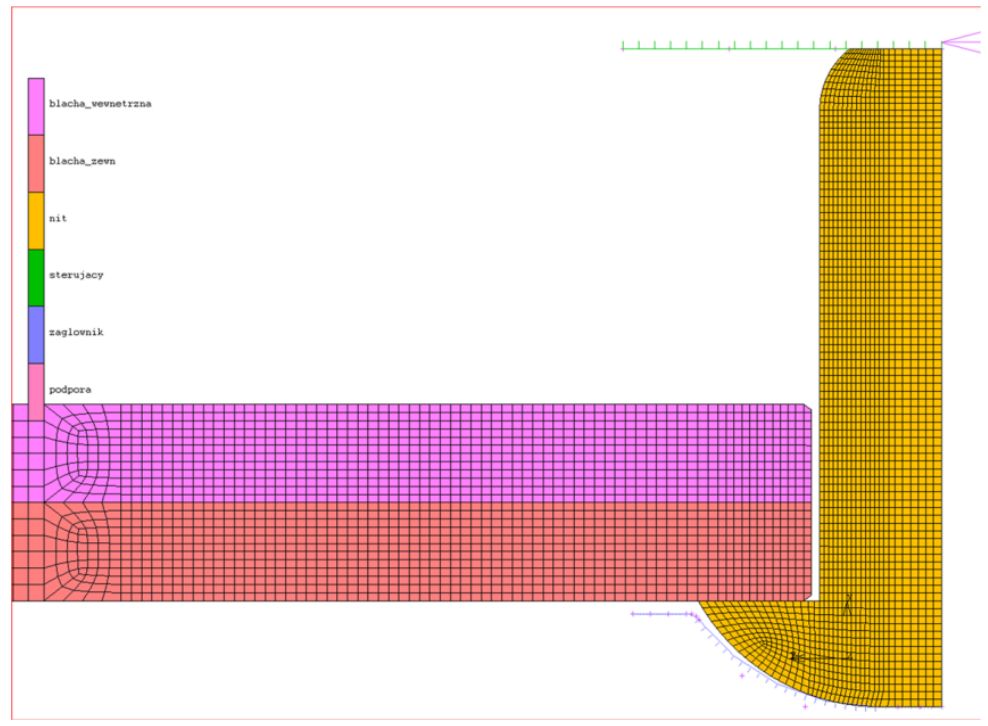

a) 


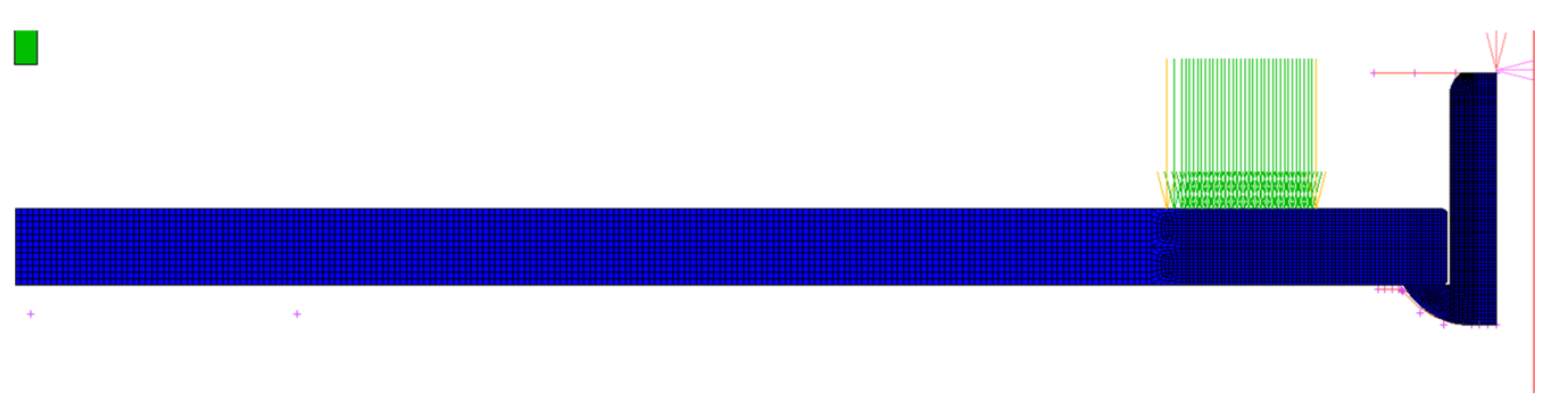

b)

Fig. 1. The FE model, a) central part, b) whole model and boundary conditions

The nonlinear implicit algorithm (MSC MARC) was used to simulate quasi-static riveting on the press. Contact phenomena including friction and elastic-plastic properties of the materials were taken into account. The stick-slip friction model was used with the friction coefficient equal to 0.42 for kinematic and 0.34 for static friction [9]. The material model for the sheets was prepared based on the monotonic tests performed by the team led by prof. M. Skorupa within the IMPERJA project. In the case of the rivet, the material model from [10Błąd! Nie można odnaleźć źródła odwołania.] was used.

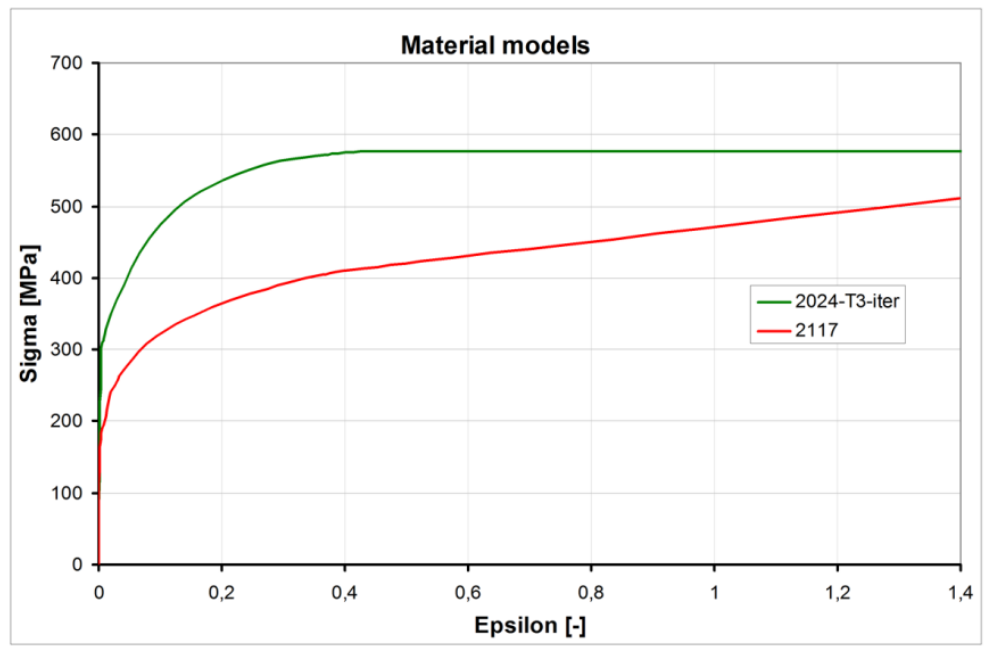

Fig. 2. Material models used in calculations

The tools used in riveting (hold-on and press stamp) were modelled as rigid surfaces. The holdon was fixed. At first, sheets were clamped near the rivet by forces distributed on the sheet surface to simulate the effect of the sleeve used in the riveting set. Then, the force controlled stamp started to squeeze the rivet. The squeezing force rose to its maximum value and then decreased to zero. The force values were selected such as to obtain the required dimensions of a driven head. The calculations were performed in a similar way as described in [8].

\section{INVESTIGATED CASES}

Both the riveting instructions and the rivet standards define diameters of holes and rivets as well as diameters of driven heads and their heights with tolerances. In the case of the Polish industry standard BN-70/1120-03, a minimum height of a driven head is specified without any tolerances. Fig. 3-4 present allowable diameters of holes and rivets as well as dimensions of driven heads according to the documents investigated. 


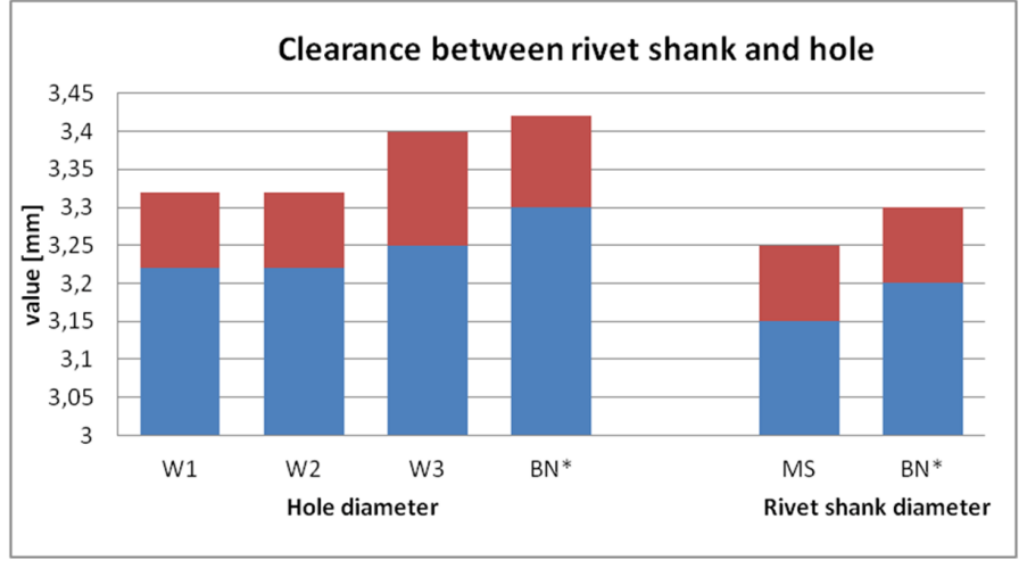

Fig. 3. Diameters of holes and rivets according to investigated documents

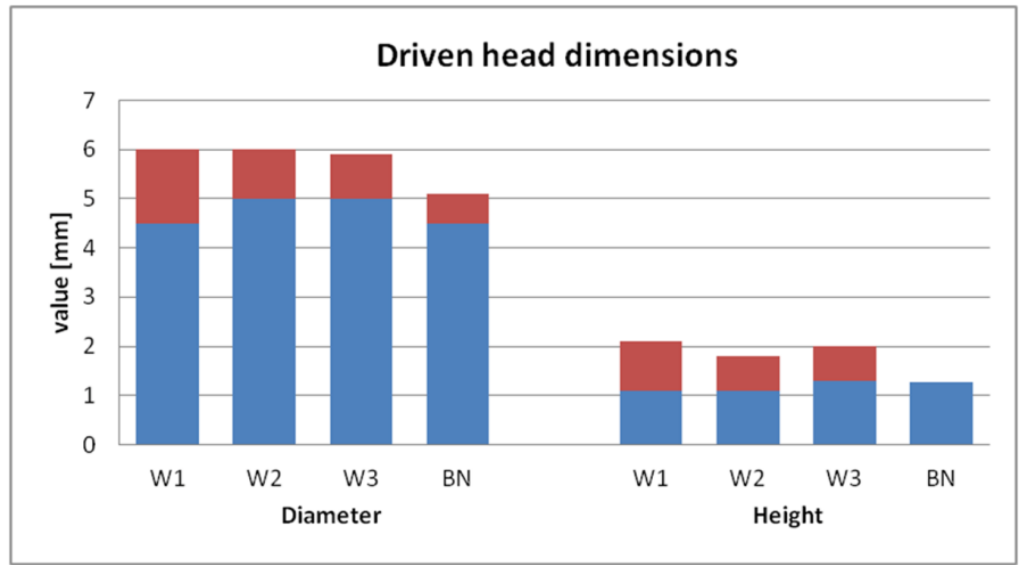

Fig. 4. Dimensions of driven heads according to investigated documents

The authors decided to analyse the cases with maximum and minimum stresses. The cases with a maximum and minimum clearance between a rivet and a hole, fulfilling requirements of at least one of the W1-W3 instructions and the MS20470 standard, were selected. It was assumed that a negative clearance (interference fit) would not occur (in such a case another rivet would be selected) and the case of a minimum clearance meant that diameters of a rivet and a hole were equal $(3.25 \mathrm{~mm})$.

The rivet length was selected with a special equitation allowing for calculating the appropriate value. In the analysed case, the W1-W3 instructions provided the same number. Then, a length closest to the calculated value was selected out of those indicated in the rivet standard. In this case it was $7.14 \mathrm{~mm}$. It is a supplementary length, which requires an additional symbol in the rivet length code. The tolerance of the rivet length is $0.25 \mathrm{~mm}$ and this parameter was neglected in the analysis. In the case of the BN-70/1120-03 standard, the rivet length for the analysed joint was 6 $\mathrm{mm}$. Only the nominal value is specified by this document.

During riveting, the height of a driven head decreases and its diameter increases as squeezing force increases. A driven head diameter or height reaches its limit value first depending on a clearance between a rivet and a hole. In order to determine the cases when the squeezing force is maximal/minimal, the calculation with high squeezing force was performed and the graph of momentary diameter and height of a driven head as a function of squeezing force was prepared. The graphs were corrected for elastic spring back. This calculation was performed for minimal and maximal clearance according to the W1-W3 instructions as well as for the minimal clearance and other parameters according to the Polish industry standards, designated as BN. 
In the case of the minimal clearance, the diameters of a rivet and a hole are the same for the W1-W3 instructions (with the assumption that the negative clearance, i.e. interference fit, will not occur). In the case of the maximal clearance, the limit values are different for the W1-W2 and W3 instructions and separate calculations for these cases were performed.

The limit values of the driven head diameter and height defined in the investigated documents were marked in the graph (Fig. 5). Based on this graph, the cases with maximal and minimal squeezing force that fulfil the requirements of at least one of the W1-W3 instructions (or BN standard) were determined. Separate cases were selected for the maximal and minimal clearance (W1-W3 instructions). In the case of the BN standard, only the cases for the minimal clearance were analysed. The cases determined in this way were collected in Table 1 . The name of the case indicates the instructions whose requirements were fulfilled.

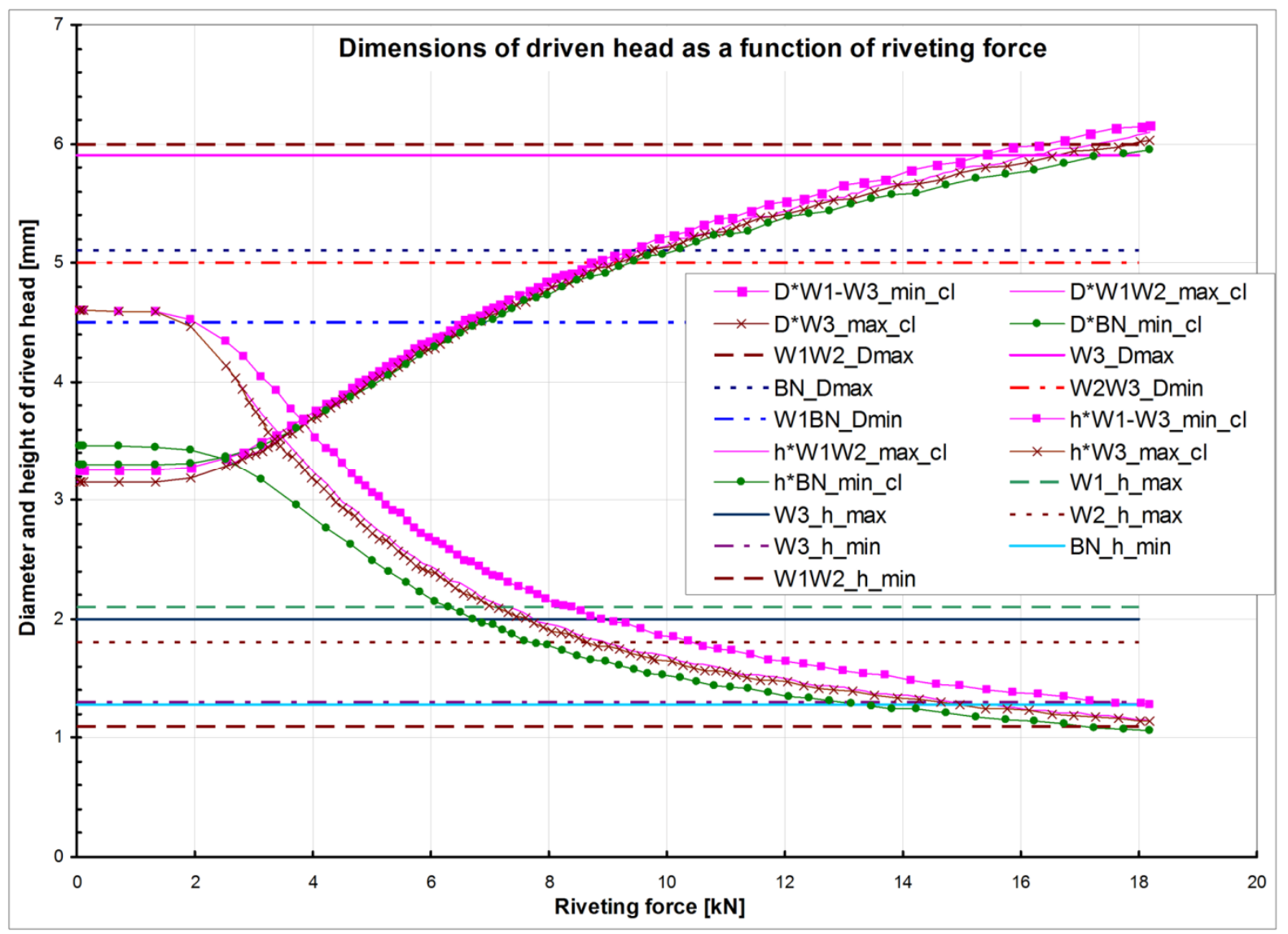

Fig. 5. Diameter and height of driven head as a function of squeezing force. Horizontal lines mark limit values according to analysed documents

\footnotetext{
Marking code: 1) Diameter and height curves: ' $\mathrm{D}^{*}$ ' - diameter, ' $\mathrm{h}$ ' - height, 'W1-W3' - clearance according to W1-W3 instructions, 'max_cl' - maximal clearance,

examples: 'D*W1-W3_min_cl' - Diameter as a function of force, minimal clearance according to $\mathrm{W} 1, \mathrm{~W} 2$ and $\mathrm{W} 2$ instructions

2) Horizontal lines: 'W1BN' - according to W1 instruction and BN standard, 'Dmax' maximal diameter, 'h_min' - minimal height

examples: 'W2_h_max' - maximal height according to W2 instruction
}

The rivet length was the last investigated parameter. The calculations were performed for the length of $7.14 \mathrm{~mm}$ and $7.92 \mathrm{~mm}$ (the closest value to the calculated value, which does not require an additional mark in the length code). Moreover, the calculation for the model with a removed radius on the rivet shank end and a length of $7.14 \mathrm{~mm}$ was performed. In these three cases, the squeezing force value of $13 \mathrm{kN}$ was used. 
All the analysed cases were collected in Table 1.

Table 1. Analysed cases

\begin{tabular}{|c|c|c|c|c|c|c|}
\hline Name & $\begin{array}{c}\text { Hole } \\
\text { diameter } \\
{[\mathrm{mm}]}\end{array}$ & $\begin{array}{c}\text { Rivet } \\
\text { diameter } \\
{[\mathrm{mm}]}\end{array}$ & $\begin{array}{c}\text { Rivet } \\
\text { length } \\
{[\mathrm{mm}]}\end{array}$ & $\begin{array}{c}\text { Force } \\
{[\mathrm{kN}]}\end{array}$ & $\begin{array}{c}\text { Rivet diameter } \\
{[\mathrm{mm}] ;} \\
\text { D/Do parameter } \\
{[-]}\end{array}$ & $\begin{array}{c}\text { Driven } \\
\text { head } \\
\text { height } \\
{[\mathrm{mm}]}\end{array}$ \\
\hline \multicolumn{7}{|c|}{ Influence of driven head dimensions and clearance } \\
\hline W1W2_cl_min_Fmax & 3.25 & 3.25 & 7.14 & 16.3 & $5.99 ; 1.87$ & 1.36 \\
\hline W1W2_cl_max_Fmax & 3.32 & 3.15 & 7.14 & 17.4 & $5.99 ; 1.87$ & 1.91 \\
\hline W1_cl_min_Fmin & 3.25 & 3.25 & 7.14 & 8.4 & $4.94 ; 1.54$ & 2.08 \\
\hline W1_cl_max_Fmin & 3.32 & 3.15 & 7.14 & 7.3 & $4.65 ; 1.45$ & 2.09 \\
\hline BN_cl_min_Fmax & 3.3 & 3.3 & 7.14 & 10 & $5.09 ; 1.59$ & 1.53 \\
\hline BN_cl_min_Fmin & 3.3 & 3.3 & 6.0 & 6.9 & $4.52 ; 1.41$ & 1.96 \\
\hline \multicolumn{7}{|c|}{ Influence of rivet length } \\
\hline 1_7_14 & 3.37 & 3.15 & 7.14 & 13 & $5.57 ; 1.77$ & 1.39 \\
\hline 1_7_92 & 3.37 & 3.15 & 7.92 & 13 & $5.69 ; 1.81$ & 1.60 \\
\hline 1_7_14_cut & 3.37 & 3.15 & 7.14 & 13 & $5.56 ; 1.77$ & 1.44 \\
\hline
\end{tabular}

\section{RESULTS}

\section{Influence of the driven head's dimensions and clearance}

The radial $(\mathrm{Sr})$ and tangential $(\mathrm{St})$ stresses on the sheet surface near the driven head for the cases of clearance and driven head dimensions influence analysis have been presented in fig. 6-7.

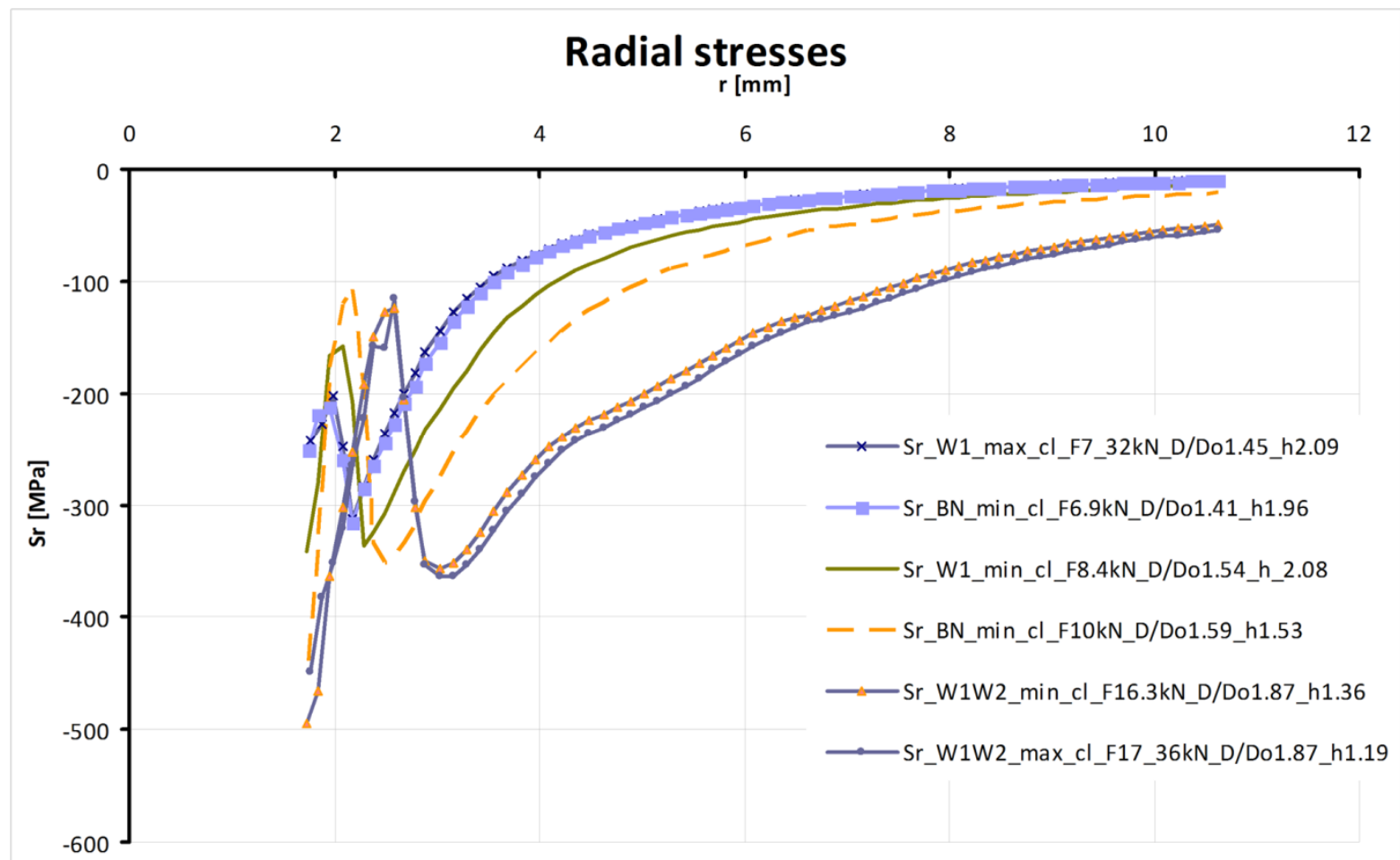

Fig. 6. Radial stresses on the sheet surface near the driven head-clearance and force influence 


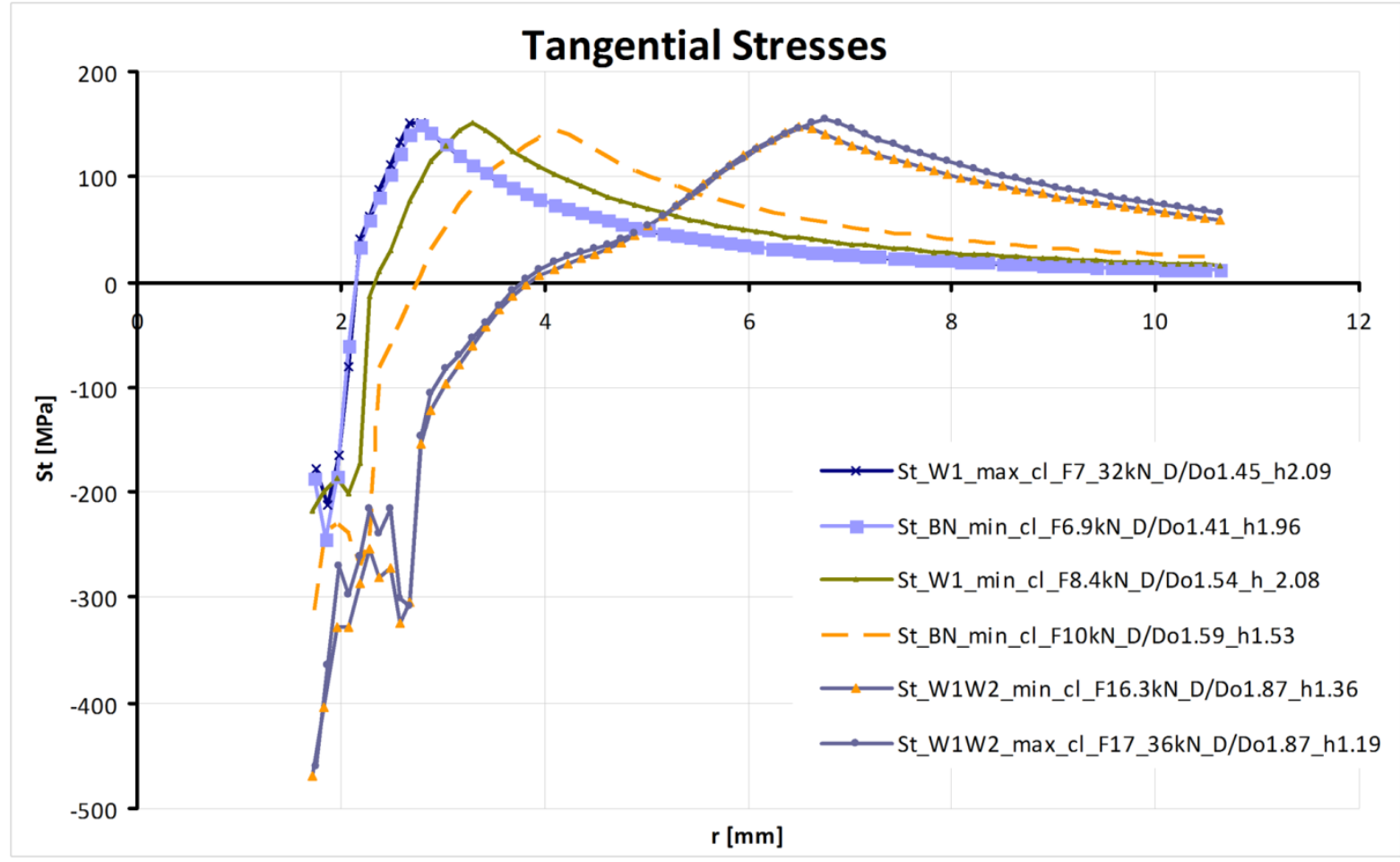

Fig. 7. Tangential stresses on the sheet surface near the driven head - clearance and force influence

The results show that residual stresses around the rivet can vary significantly within allowable riveting parameters defined in the investigated standards and instructions. This has a strong impact on the fatigue life of joint. It is particularly visible in the case of tangential stresses since the area where the tangential stresses are compressive and the place of maximum value depend on the riveting parameters. The most affective factor is the squeezing force level. Stress courses in the case of maximal and minimal clearance are similar if the squeezing force level is approximately the same. Some differences exist for low forces while in the case of high forces stress courses are almost the same. In the cases of calculations with dimensions according to the Polish standards, stress courses are placed near the courses with low forces according to the W1-W3 instructions.

\section{Influence of length}

Fig. 8-9 present radial and tangential stress courses on the sheet surface near the driven head for the cases of the length influence analysis. For the same squeezing force, neither the difference of one length interval nor the shape of the shank end, have any significant influence on the residual stresses. The biggest difference is in the local maximum stress level near the rivet. 


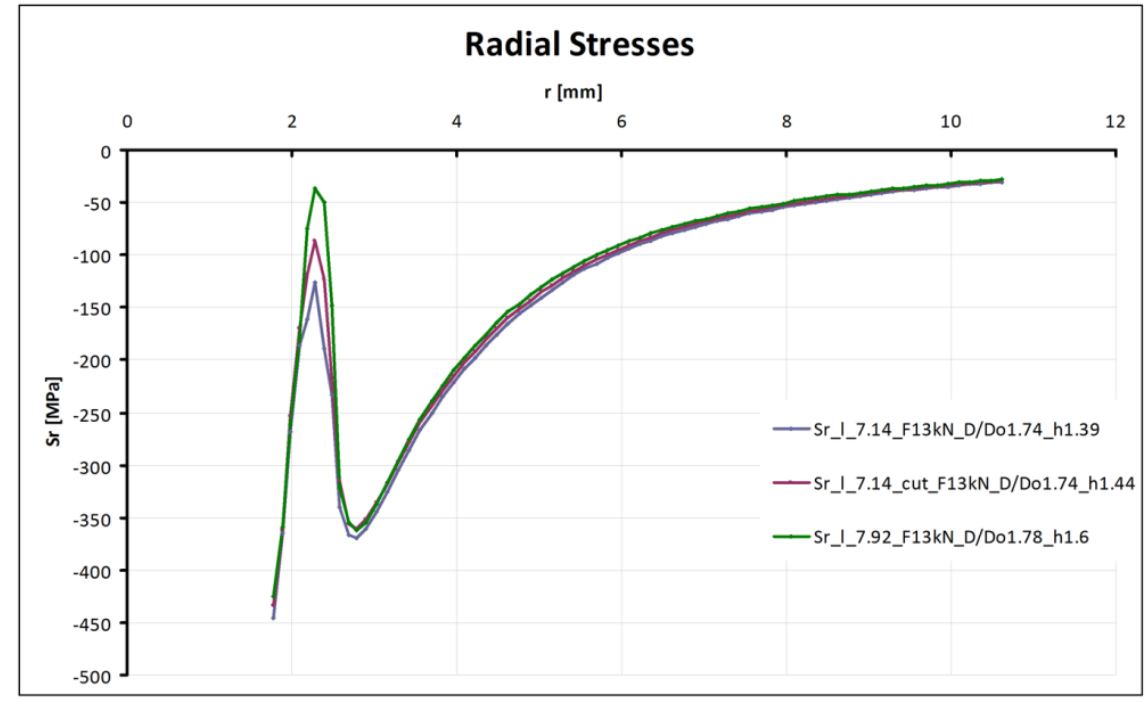

Fig. 8. Radial stresses on the sheet surface near the driven head-rivet length influence

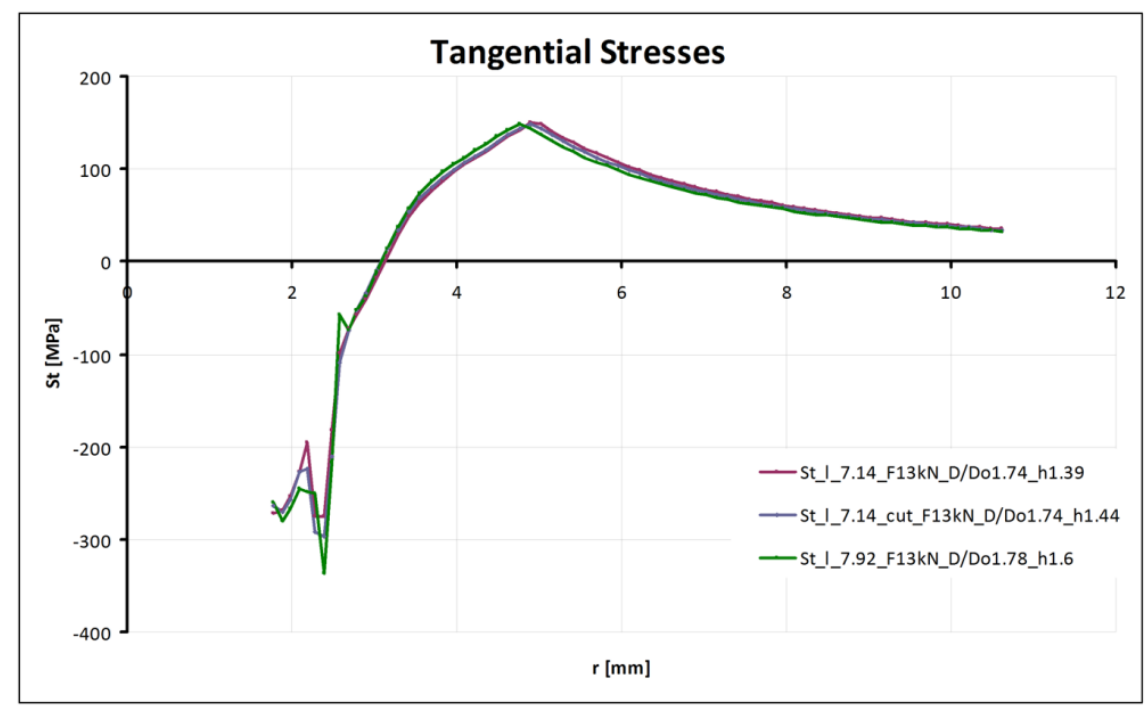

Fig. 9. Tangential stresses on the sheet surface near the driven head-rivet length influence

\section{CONCLUSIONS}

The paper presents the analysis of a stress variation range around the rivets for which the requirements of the selected instructions and standards are fulfilled. The results show that the stress courses can vary considerably depending on riveting parameters. This is important since the residual stress system is directly connected with the fatigue life of joints.

The results show that the most decisive parameter is the squeezing force value. The clearance between the rivet shank and the hole does not affect significantly stress courses when the squeezing force (driven head dimensions) is similar.

The comparison of stress curves obtained for the parameters according to the W1-W3 instructions and the Polish standards deserves attention. In the case of the Polish standards, the range of stress variation is lower than for the W1-W3 instructions, but stress curves are located near the curves for low forces, which is disadvantageous from the fatigue point of view. It might 
be possible to significantly improve fatigue properties of joints riveted according to the Polish standards without reducing tolerance (which generates additional cost) by shifting the specification range towards values connected with higher forces. The case marked as BN was created only for the comparison purposes and does not exist in industrial practise. The Polish standards define a slightly different geometry of the rivet head and a rivet diameter equal to 3 or $3.5 \mathrm{~mm}$ (not 3.2 $\mathrm{mm})$. These differences do not seem to affect the stress courses in a meaningful way.

\section{ACKNOWLEDGMENTS}

The authors express their acknowledgments to Mr Damian Przybysławski, student of the Military University of Technology in Warsaw for his work on preparing the FE model used in the presented analysis as part of his student traineeship.

\section{BIBLIOGRAPHY}

1. Muller R.P.G., Hart-Smith L.J., Making fuselage riveted lap splices with 200-year crack-free fatigue lives, ICAF 97: Fatigue in New and Ageing Aircraft, Vols I and Ii: Vol I: Lecture Papers, Vol Ii: Poster Papers, (1997) 499-522.

2. Skorupa M., Skorupa A., Machniewicz T., Korbel A., Effect of production variables on the fatigue behaviour of riveted lap joints, International Journal of Fatigue, 32 (2010) 996-1003.

3. Muller R., „An Experimental and Analytical Investigation on the Fatigue Behaviour of Fuselage Riveted Lap Joint”, Ph.D. thesis, TU Delft, Netherlands, 1995.

4. Rans C. D. The Role of Rivet Installation on the Fatigue Performance of Riveted Lap Joints. $\mathrm{PhD}$ thesis, Carleton University Ottawa, Ontario, Canada, 2007.

5. Szymczyk E. , Numeryczna analiza lokalnych zjawisk fizycznych $w$ połaczeniach nitowych konstrukcji lotniczych (in Polish, Numerical analysis of local physical phenomena in riveted joints used in aerospace structures). Wyd. WAT, 2013, ISBN 978-83-62954-70-4

6. Kaniowski J. Comparision of Selected Rivets and Riveting Instructions. Fatigue of Aircraft Structures Monographic Series A. Niepokólczycki (Ed.), Institute of Aviation Scientific Publication, ISSUE 2014.

7. Li G., Shi G.Q., Bellinger N.C., Stress in Triple-Row Riveted Lap Joints Under the Influence of Specific Factors, Journal of Aircraft, 48 (2011) 527-539.

8. Wronicz W., Kaniowski J. (2011). Experimental and Numerical Study of Strain Progress During and After Riveting Process for Brazier Rivet and Rivet with Compensator - squeezing force and rivet type effect. A. Niepokólczycki (Ed.). Fatigue of Aircraft Structures, Monographic Series, ISSUE 2011, pp. 166-190, ISSN (Online) 2300-7591, DOI: 10.2478/v10164-010-0047-1, August 2011.

9. ASM Handbook, Volume 18, „Friction, Lubrication, and Wear Technology”, 1995

10. Fárek J.: FE-Modelling Methodology of Riveted Joints. Czech Aerospace Proceedings. Journal for Czech Aerospace Research, No 2/2010, pp. 12-16 